\title{
Environmental assessment of the Tung cultivation through life cycle analysis
}

\author{
Marcelo Bernál ${ }^{1}$, Rosana de Cassia de Souza Schneider ${ }^{2^{*}}$, Enio Leandro Machado ${ }^{2}$ \\ ${ }^{1}$ Environmental Technology Program, Santa Cruz do Sul University. \\ ${ }^{2}$ Department of Chemistry and Physics, Santa Cruz do Sul University, Santa Cruz do Sul. \\ *Corresponding author E-mail: rosana@unisc.br
}

Copyright $\odot 2014$ Marcelo Bernál1 et. al. This is an open access article distributed under the Creative Commons Attribution License, which permits unrestricted use, distribution, and reproduction in any medium, provided the original work is properly cited.

\begin{abstract}
Over the past few decades, conventional agriculture has been facing serious crises caused by numerous factors, including poor soil management and the excessive application of pesticides. Thus, alternative production systems have been developed, including agroforestry systems, especially those that produce both energy and food. The objective of this study was to environmentally evaluate the culture of Aleurites fordii Hemls. (Tung) using the Life Cycle Assessment method with the SimaPro 7.3.2 software. The results revealed that in family farms that use less mechanization to harvest crops, the primary category of environmental impact was land use, which included the removal of animal and vegetable species and ecosystem changes. The full impact of this category was $1741.21 \mathrm{~m} 2 \mathrm{yr}$ PDF (potentially disappeared fraction). Subsequently, prognostics were established for the reduction of such impacts, and we conclude that Tung has a high potential for agricultural installation with high responsibility to the environment.
\end{abstract}

Keywords: Environmental factors, Aleurites fordii Hemls, Life Cycle Management, Tung.

\section{Introduction}

In the last 70 years, productive models have undergone considerable modifications, especially those for agricultural areas. In fact, an objective of the green revolution was the expansion of agricultural areas, and in Brazil, millions of hectares of native forests were occupied in the name of agriculture expansion.

To realize this otherwise hypothetical conjecture, agroforest systems (AFS) are an opportunity to improve diversification. The interaction between several natural and productive ecosystems is the model considered to be "peasant agriculture" [1].

Peasant cooperatives encourage agroforest systems, which include species used for food and for energy production. With respect to energy production, we can highlight Aleurites fordii, which is known as oil producer.

Tung is from Asia, and 33\% of its fruit is oil. Tung oil is inedible and is used for varnishes, leather and paint manufacture and is an important wood preservative. This plant has 30 productive years, and its apex of productivity is around the 12 th year.

The soil and climate requirements of this culture are adequate for Brazilian production, but the price for the chemical industry is not attractive. The Brazilian Institute of Geography and Statistics (IBGE) stated that in 2010, 123 hectares had been planted, with a potential productivity of $2,585 \mathrm{~kg}$ of dry fruit per hectare. Therefore, the environmental assessment of this culture, which is in its initial stages of production in South Brazil, is important and can contribute to the diversification of the agro forest systems.

Life Cycle Analysis (LCA) is a tool for environmental assessment that can be used for product or process evaluation and that considers all life periods. This tool is appropriate for analyzing Tung plantations until the beginning of oil production.

Using LCA, it is possible to consider the raw material extraction and the recycling and disposal of waste, as well as the packaging, manufacture and commercialization. The inventory data contain information about potential environmental impacts, but further study is needed to recognize the impact categories, for example, global warming, acidification and land use. Each category contains aggregate information related to biodiversity, gas production, energy use, soil 
occupation, and other factors that potentially impact the environment. This tool already is used in the agricultural production assessment of energetic plants, such as Brazilian soybean and Malaysian oil palm [2], Chilean sunflower and Jatropha [3], Italian sunflower [4] and Grecian rapeseed, sunflower and soybean [5].

For energetic plants that can be used for biofuel production, agricultural production is the major environmental problem because while the use and industrial production of biofuels have a lower climate change potential, they can be responsible for other environmental damages [6].

Unlike other previous studies, the principal focus of our study is agricultural production and its environmental impact. Our hypothesis is that obtaining more sustainable conditions in family farms is possible when there is local production, transport reduction and improvement in the use of whole plants in other activities on the farms, as well as small-scale biofuel production that may facilitate agricultural diversification without competition with food crops [7].

Therefore, in partnership with the University of Santa Cruz do Sul and a cooperative (Cooperfumos located in Santa Cruz do Sul - RS, Brazil), an experimental area with Tung plants (Aleurites fordii Hemls.) was monitored. The objective of this study was to environmentally evaluate the culturing of Tung using LCA and to determine the contribution of energy-producing plants with long life cycles to the diversification of the regional agriculture.

\section{Material and methods}

\subsection{Data inventories}

The experimental area was located in the Cooperfumos Cooperative and the total area was 41.5 ha, of which there were 0.15 ha planted with Tung. The information for the inventory data matrix was obtained between July 2008 and July 2012. The procedures, observations, input and output in the agricultural experiment were registered in an electronic planner. The phase considered in this study consisted of seedling preparation through fruit harvest.

The data were organized in six distinct groups involving all productive process over the four years. The groups were as follows: Seedling preparation: First step, involving 50 seedlings prepared in low density polyethylene packing. The insumes were quantified individually; Soil preparation: Second step of production, which primarily includes fuel consumption and alterations in the physical structure of the soil; Plantation: In this step, there is no direct consumption of insumes or resources. There is only human work because this system has little mechanization; Irrigation: This step was compiled independent of the plantation to better determine water consumption because this input occurs more frequently during the first months of implantation; Conduction: This step involved understanding the process between the implantation and pre-harvesting of fruits; Harvest: This step consisted of the fruit harvest in the fourth year of production. There are inputs related to human work, transport and storage.

\subsection{Environmental impact assessment}

In the productive process of Aleurites fordii Hemls, we used the software SimaPro 7.3.2. This tool was chosen because there are a considerable number of papers that have employed this tool, and it is applicable for investigating this process. The damage categories used in this software were as follows [5]: Damage to human health: expressed in DALYs (Disability Adjusted Life Years) and indicates the number of lost years lost plus the number of the years lived with incapacity; Damage to ecosystem quality: expressed in species lost in a determined area and over a determined period of time; Damage to Resource: expressed in energy needed for the mineral extraction and fossil fuel used in the process; The method selected for data processing was the Ecoindicator-99. The indicators used were as follows: Carcinogenic the representation in DALYs per $\mathrm{kg}$ of carcinogenic compound emissions for air, water and soil; Respiratory effect organic - the effects caused by summer smog due to the organic substances that are released into the atmosphere; Respiratory effect - inorganic: the effects caused by winter smog due to the release of particulate material, sulfur and nitrogen oxides to the atmosphere; Climatic change - expressed in DALYs per kg of emission; Radiation - the effects caused by radioactivity; Ozone Layer - the effects caused by ultraviolet radiation as a result of gas emissions that destroy the ozone layer; Eco toxicity - the ecosystem quality destruction through the release of toxic compounds to air, water and soil; Acidification/ eutrophication - expressed in PDF (Potentially Disappeared Fraction) in $\mathrm{m}^{-2} \mathrm{ano}^{-1} \mathrm{~kg}^{-1}$. This category measures the release of acidifying substances into the air; Land use - This is a complex category because it expresses the impact in the biodiversity caused by assessment activity. Land use is expressed in PDF $\mathrm{m}^{-2}$ ano-1 of occupation suppression; Minerals - the surplus energy caused by the reduction of mineral reserves; Fossil fuel - the extracted surplus energy as result of resource quality reduction.

\section{Results and discussion}

\subsection{Data inventory}

In the experimental area, 50 trees were harvested after four years for a total of $16.95 \mathrm{~kg}$ of fruits per tree unit. The estimated oil production was $847,3 \mathrm{~kg} \mathrm{ha}^{-1}$. This is good production because the production of Tung oil tends to increase until the $15^{\text {th }}$ year [8]. The inventoried data obtained over the four years of assessment are provided in Table 1. 
It was observed for this culture that the impact was generally low. This observation is justified by the concentration of impacts in the initial process of seedling production and plantation.

Compared to the other oleaginous cultures, it was observed that in Tung production, there was less insume consumption and less crop tillage, which have a significant effect on eutrophication, especially due to the use of fertilizers and mechanical operations [9]. Ant control was effectively conducted using the pesticide Fipronil (Fenil Pirazol), which is in Toxicological Class III.

Table 1: Summary of inventory data and activities registered over four years of Tung oil production.

\begin{tabular}{|c|c|c|c|}
\hline Insumes/Activities & Description & Insumes/Activities & Description \\
\hline Composting & $20.0 \mathrm{~kg}$ transported for $120 \mathrm{~km}$ & Electric energy & $87.4 \mathrm{~kW} \mathrm{~h}^{-1}$ \\
\hline Soil & $5.0 \mathrm{~kg}$; transported by tractor for $200 \mathrm{~m}=0.1 \mathrm{~h}$ & Mechanized farm 0.15 ha & $3.5 \mathrm{~L}$ of fuel \\
\hline Polyethylene bag & 50 units; transported by car for $15 \mathrm{~km}$ & Plowing ( 3 blades, hard) & $3.5 \mathrm{~L}$ of fuel \\
\hline Seeds & $500 \mathrm{~g}$; transported for $100 \mathrm{~km}$ & Soil dialing ( 2 cuts) ( 28 disk) & $2.4 \mathrm{~L}$ of fuel \\
\hline Wood box & 2.08 box $\left(\mathrm{R} \$ 1.10\right.$ box $\left.^{-1}\right)$; transported for $100 \mathrm{~km}$ & Holes preparation & $2.0 \mathrm{~L}$ of fuel \\
\hline Irrigation water & $6,990 \mathrm{~L}$ & Ant control & $\begin{array}{l}5.6 \mathrm{~kg} \text { of } \\
\text { formicide }\end{array}$ \\
\hline $\begin{array}{l}\text { Transport / } \\
\text { storage }\end{array}$ & $0.6 \mathrm{~L}$ of diesel fuel & & \\
\hline
\end{tabular}

It is easy to see why the impact was low because seedling production and transplanting occurs once in fifteen years. Therefore, the impact is low; however, the impact is not completely known. Recognizing the environmental impact observed in a Tung farm is important for the reduction of some impacts and to improve the incentives for Tung production in a region.

The fuel consumption in this agricultural experiment was low compared to other studies that use tractors more often [10]. Moreover, the fuel had high sulfur content. In the research period, the diesel that was used in Brazil contained $1800 \mathrm{ppm}$ of $\mathrm{S}$.

The total amount of irrigation over the four years was low, but different water stress levels in Tung trees can affect the oil quality, which has also been observed in olive trees [11].

\subsection{Environmental impact assessment}

The Tung farm inputs were available in six groups, as presented in the methodology. For evaluation, we used three damage categories and ten indicators, and the process was divided into three stages: seedling plantation and transplant to soil (1), conduction of farm of the plantation to harvest (2), and fruit harvest and storage (3). Table 2 relates the impact weight with the categories in the three stages of the study.

In the LCA of Tung plantation, 77.66 pt. was distributed between the different impact categories, in which the land use was the primary value. Ecosystem suppression by operations during soil preparation is the major focus for improvements in the agricultural production of Tung oil.

We highlight the proportions that each step takes in the process, that is, $95.26 \%$ of the impact is in the first step, whereas the operation of the farm from plantation to harvest was $4.0 \%$ and from harvest and storage was $0.74 \%$. These results confirm that plants with long life cycles have less impact than plants with short life cycles.

For environmental sustainability, many research groups evaluate the impact of climatic change on agriculture in various parts of the world as well as the climate impact for which agriculture is responsible [12-14]. With respect to Tung plantations, the impact on climatic change is low but is not irrelevant considering that the Tung productivity in family farms can be high in South Brazil.

Damages as a result of Tung production are presented in Table 2. The damage units used here are the same as those used by the World Health Organization (WHO) and the World Bank. Analyzing the damages, it is observed that land use produces the most damage units; reinforcing the conclusion that implantation has the most significant impact when plants with long life cycles are grown.

Similarly, in the "quality of the ecosystem" category, the stage of plantation and transplanting of seedlings causes the most damage compared to the other stages of the process, and this result also confirms that land use is the step that requires the most attention in Tung production. With respect to the human health category, in the plant growth after seedling transplantation until harvest, there was more impact because the unique work in this stage is the manual care of the plants (Table 2).

The diversity in land use varies from mechanized large-scale farms to small-scale farming systems characterized by low technology and farm inputs.[15] The reality of this region in South Brazil is that the family farms and Tung production can be adapted with low impact.

The statistical evaluation of the data was performed using the SimaPro software package using Monte Carlo simulations. The confiability of the results are presented in Table 3. The variation coefficient (VC) was minor when the impact or damage was major, for example, the land use presented a VC of $0.35 \%$ and carcinogens of $41.6 \%$, and the impacts were $77.65 \mathrm{pt}$ and $0.056 \mathrm{pt}$, respectively. These results show that the means for the main categories are confiables. 
Likewise, in the damage categories, it was observed that the resource consumption presented a major VC because there was a low allocation of data in this category and the minimum absolute dispersion also resulted in significant proportions.

According to the Monte Carlo simulations, the dispersion values are considered low, especially the VC (1.52\%), as presented in Table 3. The impacts are statistically analyzed in unique scores, which show that the results of impacts and damages are accurate.

Table 2: Weighted and Damages as results for impact categories in the Tung production.

\begin{tabular}{|c|c|c|c|c|}
\hline Impact category & Total & Seedling plantation & Conduction & Harvest and storage \\
\hline Carcinogenic (pt) & 0,0563 & 0,0132 & 0,0431 & $3,38^{-07}$ \\
\hline Organic inhalable (pt) & 0,0042 & 0,0023 & 0,0019 & $1,88^{-08}$ \\
\hline Inorganic inhalable $(\mathrm{pt})$ & 0,9402 & 0,4471 & 0,4931 & $7,15^{-06}$ \\
\hline Climatic changes (pt) & 1,1405 & 0,1582 & 0,9824 & $2,19^{-06}$ \\
\hline Radiation (pt) & 0,0008 & 0,0001 & 0,0007 & $1,77^{-09}$ \\
\hline Ozone Layer (pt) & 0,0002 & 0,0001 & 0,0002 & $1,08^{-09}$ \\
\hline Ecotoxicity (pt) & 0,0075 & 0,0011 & 0,0065 & $1,29^{-08}$ \\
\hline Acidification/ Eutrophication (pt) & 0,0219 & 0,0125 & 0,0094 & $1,67^{-07}$ \\
\hline Land use (pt) & 77,6583 & 76,9504 & 0,1027 & 0,605216 \\
\hline Minerals (pt) & 2,0718 & 0,4333 & 1,6385 & $6,28^{-06}$ \\
\hline Total (pt) & 81,902 & 78,0183 & 3,2785 & 0,6052 \\
\hline Carcinogenic (DALY) & $4,77^{-07}$ & $1,12^{-07}$ & $3,65^{-07}$ & $2,86^{-12}$ \\
\hline Organic inhalable (DALY) & $3,58^{-08}$ & $1,93^{-08}$ & $1,65^{-08}$ & $1,59^{-13}$ \\
\hline Inorganic inhalable (DALY) & $7,95^{-06}$ & $3,78^{-06}$ & $4,17^{-06}$ & $6,05^{-11}$ \\
\hline Climatic changes (DALY) & $9,65^{-06}$ & $1,34^{-06}$ & $8,31^{-06}$ & $1,85^{-11}$ \\
\hline Radiation (DALY) & $6,44^{-09}$ & $7,79^{-10}$ & $5,66^{-09}$ & $1,5^{-14}$ \\
\hline Ozone Layer (DALY) & $2,05^{-09}$ & $7,03^{-10}$ & $1,34^{-09}$ & $9,17^{-15}$ \\
\hline Ecotoxicity (DALY) & 0,1691 & 0,024 & 0,1451 & $2,88^{-07}$ \\
\hline Acidification/utrophication (PDF m2yr) & 0,4919 & 0,2808 & 0,2111 & $3,75^{-06}$ \\
\hline Land use (PDF m2yr) & 1741,218 & 1725,345 & 2,3036 & 13,569 \\
\hline Minerals (MJ exceed) & 3,5994 & 0,7528 & 2,8466 & $1,09^{-05}$ \\
\hline \multicolumn{5}{|l|}{ Damage categories } \\
\hline Human health (pt) & 2,1423 & 0,621 & 1,5213 & $9,71^{-06}$ \\
\hline Ecosystem quality (pt) & 77,6878 & 76,964 & 0,1186 & 0,6052 \\
\hline Resource use (pt) & 2,0718 & 0,4333 & 1,6385 & $6,28^{-06}$ \\
\hline Total & 81,902 & 78,0182 & 3,2785 & 0,6052 \\
\hline
\end{tabular}

Table 3: Statistical parameters per impact and damage categories.

\begin{tabular}{|c|c|c|c|c|c|c|c|c|}
\hline Impact categories & Unit & Mean & Median & SD & $\mathrm{VC}(\%)$ & $2,5 \%$ & $97,5 \%$ & Error \\
\hline Human health & $\mathrm{Pt}$ & 2,13 & 2,08 & 0,386 & 18,1 & 1,56 & 3,04 & 0,0057 \\
\hline Ecosystems quality & $\mathrm{Pt}$ & 77,7 & 77,7 & 0,272 & 0,351 & 77,2 & 78,3 & 0,0001 \\
\hline $\begin{array}{l}\text { Resource use } \\
\text { Damage categories }\end{array}$ & $\mathrm{Pt}$ & 2,09 & 1,82 & 1,02 & 48,7 & 1,02 & 4,66 & 0,0154 \\
\hline Total scores & $\mathrm{Pt}$ & 81,9 & 81,7 & 1,24 & 1,52 & 80,3 & 85,2 & 0,00048 \\
\hline
\end{tabular}

\subsection{Environmental prognostics}

Considering that the process already used an improvement of other models that occur in a tree plantation, it is possible to define some further actions that would increase the environmental efficiency and mitigate the environmental impacts. Packing substitution is one alternative, even though in the impact matrix, the packing is not relevant. The use of reusable plastic tubes is better because the efficiency is superior. The same seedling quantities can be produced in a reduced planting area, and the solid residues are less compared to plastic bags, as was used.

During harvest and storage, husks can be separated (40\% of the fruit). The husk of the Tung fruit creates a great volume of vegetable residue. Therefore, the husks can be composted and used as nutrition for the Tung plant. The recycling of husks through composting processes is an excellent option for the vegetable residue to be transformed in insumes in the same plantation. Therefore, the elements extracted by the harvest return to the system, which reduces the nutritional deficit as well as contributes to the equilibrium of the system. This scenario is ideal for production. An atmosphere simple input allowed the repositioning of an output of the first phase of the oil extraction.

The Tung husk biomasses are considered a "residual or secondary product". However, if is biomass is not recycled in the same plantation, it is possible transform it into adsorbent materials[16], bioethanol [17], or other products. Moreover, less soil turnover is important to decrease the impact because the land use is responsible for more than $90 \%$ of the total impact of the productive system. During soil turnover, there are changes in the microflora, soil physical structure, 
hydrological cycle, and other factors. In addition, there are differences in the amount of carbon stored in the soil and vegetation [14].

Finally, the impacts associated with ant control were measured in the LCA as low, although it is important to highlight that this impact can be reduced with other natural controls. Species that are considered pests in a particular agro ecosystem can be effective biological control agents under others[18].

\section{Conclusion}

Considering the initial estimation of the Tung plantation impacts obtained by inventory and LCA with the SimaPro software, there is great opportunity for Tung production with less impact by familiar agricultural producers. In regions where there is a agro forest program that includes energetic species, Tung is a good option because this plant has a long life cycle and lower negative impacts compared with short life cycle species.

The major impact is because of the land use, which will occur again after ten years. The other impact categories and damages are minimally affected during this intervening time period because there is low fuel consumption and many activities are manual. We highlight that the manual activities, carried out by experienced producers, are a significant environmental advantage compared to productions that are highly mechanized and on a large scale; furthermore, in addition to social attributes, such mechanization also causes major environmental impacts.

\section{Acknowledgements}

We would like to thank $\mathrm{CNPq}$ for the scholarships given to $\mathrm{M}$. B. We gratefully acknowledge support provided by CNPq. We additionally thank the FAP/UNISC program for research support and Productivity in research CNPQ $(306178 / 2012-5)$.

\section{References}

[1] F.S. Görgen, Os novos desafios da agricultura camponesa. 3 ed., Porto Alegre, 2004.

[2] B. Mattsson, C. Cederberg, and L. Blix, "Agricultural land use in life cycle assessment (LCA): case studies of three vegetable oil crops", Journal of Cleaner Production, Vol. 8, No. 4, (2000), pp. 283-292, available online: http://dx.doi.org/10.1016/S0959-6526(00)00027-5.

[3] A. Iriarte, J. Rieradevall, and X. Gabarrell, "Life cycle assessment of sunflower and rapeseed as energy crops under Chilean conditions", Journal of Cleaner Production, Vol. 18, No. 4, (2010), pp. 336-345, available online: http://dx.doi.org/10.1016/j.jclepro.2009.11.004 .

[4] P. Spugnoli, R. Dainelli, L. D'Avino, M. Mazzoncini, and L. Lazzeri, "Sustainability of sunflower cultivation for biodiesel production in Tuscany within the EU Renewable Energy Directive", Biosystems Engineering, Vol. 112, No. 1, (2012), pp. 49-55, available online: http://dx.doi.org/10.1016/j.biosystemseng.2012.02.004 .

[5] T. Tsoutsos, V. Kouloumpis, T. Zafiris, and S. Foteinis, "Life Cycle Assessment for biodiesel production under Greek climate conditions", Journal of Cleaner Production, Vol. 18, No. 4, (2010), pp. 328-335, available online: http://dx.doi.org/10.1016/j.jclepro.2009.11.002 .

[6] D. Spinelli, S. Jez, and R. Basosi, "Integrated Environmental Assessment of sunflower oil production", Process Biochemistry, Vol. 47, No. 11, (2012), pp. 1595-1602, available online: http://dx.doi.org/10.1016/j.procbio.2011.08.007.

[7] J.A. Kaercher, R.d.C.d.S. Schneider, R.A. Klamt, W.L.T. da Silva, W.L. Schmatz, M. da Silva Szarblewski, and E.L. Machado, "Optimization of biodiesel production for self-consumption: considering its environmental impacts", Journal of Cleaner Production, Vol. 46, No. 0, (2013), pp. 74-82, available online: $\mathrm{http}: / / \mathrm{dx}$. doi.org/10.1016/j.jclepro.2012.09.016

[8] C.G. Júnior, "Contribuição para o estudo da cultura do tungue", Anais da Escola Superior de Agricultura Luiz de Queiroz, Vol. 3, No., (1946), pp. 8, available online: http://dx.doi.org/10.1590/S0071-12761946000100029 .

[9] P. Goglio, E. Bonari, and M. Mazzoncini, "LCA of cropping systems with different external input levels for energetic purposes", Biomass and Bioenergy, Vol. 42, No. 0, (2012), pp. 33-42, available online: http://dx.doi.org/10.1016/j.biombioe.2012.03.021 .

[10] G. Larsson and P.A. Hansson, "Environmental impact of catalytic converters and particle filters for agricultural tractors determined by life cycle assessment", Biosystems Engineering, Vol. 109, No. 1, (2011), pp. 15-21, available online: http://dx.doi.org/10.1016/j.biosystemseng.2011.01.010.

[11] G. Fregapane, A. Gómez-Rico, and M.D. Salvador, Chapter 6 - Influence of Irrigation Management and Ripening on Virgin Olive Oil Quality and Composition, in Olives and Olive Oil in Health and Disease Prevention. 2010, Academic Press: San Diego, 2010.

[12] S. Barrios, B. Ouattara, and E. Strobl, "The impact of climatic change on agricultural production: Is it different for Africa?" Food Policy, Vol. 33, No. 4, (2008), pp. 287-298, available online: http://dx.doi.org/10.1016/j.foodpol.2008.01.003 .

[13] P. Barnwal and K. Kotani, "Climatic impacts across agricultural crop yield distributions: An application of quantile regression on rice crops in Andhra Pradesh, India", Ecological Economics, Vol. 87, No. 0, (2013), pp. 95-109, available online: http://dx.doi.org/10.1016/j.ecolecon.2012.11.024.

[14] E. Lorencová, J. Frélichová, E. Nelson, and D. Vačkáŕ, "Past and future impacts of land use and climate change on agricultural ecosystem services in the Czech Republic", Land Use Policy, Vol. 33, No. 0, (2013), pp. 183-194, available online: http://dx.doi.org/10.1016/j.landusepol.2012.12.012 .

[15] S.N. Ngigi, H.H.G. Savenije, and F.N. Gichuki, "Land use changes and hydrological impacts related to up-scaling of rainwater harvesting and management in upper Ewaso Ng'iro river basin, Kenya", Land Use Policy, Vol. 24, No. 1, (2007), pp. 129-140, available online: http://dx.doi.org/10.1016/j.landusepol.2005.10.002.

[16] M.C. Manique, C.S. Faccini, B. Onorevoli, E.V. Benvenutti, and E.B. Caramão, "Rice husk ash as an adsorbent for purifying biodiesel from waste frying oil", Fuel, Vol. 92, No. 1, (2012), pp. 56-61, available online: http://dx.doi.org/10.1016/j.fuel.2011.07.024 .

[17] N. Sarkar, S.K. Ghosh, S. Bannerjee, and K. Aikat, "Bioethanol production from agricultural wastes: An overview", Renewable Energy, Vol. 37, No. 1, (2012), pp. 19-27, available online: http://dx.doi.org/10.1016/j.renene.2011.06.045.

[18] I. Perfecto and A. Castiñeiras, Deployment of the predaceous ants and their conservation in agroecosystems, in Conservation Biological Control. 1998, Academic Press: San Diego, 1998. 